\title{
Success and failures in urban transport planning in Europe-understanding the transport system
}

\author{
HERMANN KNOFLACHER \\ Institute for Transport Planning and Traffic Engineering, University of \\ Technology, Vienna A-1040 \\ e-mail: hermann.knoflacher@ivv.tuwien.ac.at
}

\begin{abstract}
Technological determinism has become a kind of religion for many people since it appears to offer solutions for societal problems as never before in history. Transport is one of the fascinating technology branches developed during the last 200 years. Effortless movement over long distances has become possible for car users as long as cheap fossil energy is available. However, the effect of fast transport on urban structures and society was not taken into account when developing these technical means. Technologists and economists have used indicators for expected benefits of these fast transport modes without taking into account the real system effects on society and urban structures. Plausible assumptions and hopes instead of scientific understanding of the complex system are used in practice. In contradiction to widely held beliefs of transportation planners, there is actually no growth of mobility if counted in number of trips per person per day, no time saving by increasing speed in the system, and no real freedom of modal choice. Modal choice is dependent on physical and other structures, the artificial environment built by urban planners, transport experts and political decisions. The core hypothesis of traditional urban and transport planning 'growth of mobility', 'travel time saving by increasing speed' and 'freedom of modal choice' are myths and do not exist in the real urban and transport system. This is the reason why urban planning and transport planning based on traditional non-scientific assumptions is creating continuously not only more transport problems, but also environmental and social as well as economic problems all over the world, where these principals are applied. Urban transport planning in Europe, understanding the transport system and the solutions are presented in this paper.
\end{abstract}

Keywords. Transport planning; urban traffic; traffic flow; transport system of Europe.

\section{Introduction}

\subsection{Urban transport planning in Europe}

During the 1950s many European transport engineers educated in the United States were brought to Europe for planning their car-oriented transport. Highway capacity manuals were 
translated and applied without much understanding of the effects it would cause to the European urban structure. Traditionally, transport in European cities mainly meant the mobility of pedestrians; for example, in the Netherlands there was an emphasis on cycling but in the more mountainous or middle European areas, the reliance was on public transport, buses, trams and rail. In Western Europe urban planning prevented the repetition of the mistakes of American oriented urban development: such as car-oriented transportation planning and urban sprawl. There are only a few examples in West German cities where expressways have been built as part of the urban structure because multi-lane urban roads cut into the urban structure adversely affecting the local economy, damaging local trade and employment. In Eastern Europe the communist governments made the same mistakes and after the fall of the iron curtain in 1989 many cities had to carry the burden of wrong transport planning decisions from the past.

\subsection{Birmingham example}

An excellent example for a future oriented transport policy is Birmingham. The second biggest city in the United Kingdom, strongly dependent on car production, Birmingham built a ring motorway around the city centre, the so-called Concrete Collar. This structure damaged large parts of the urban landscape, but this drastic measure had no viable possibilities for the future. In the last decade the city government decided to break down the so-called Concrete Collar, and replace it with an extended pedestrian area. This pedestrianization resulted in large private and public investment back into the city. Birmingham is one of the good examples of futureoriented urban and transport planning. Big cities can recover from economic depression by removing wrong transport infrastructures, which strangle city development, reduce traffic safety and make urban life less attractive. The bullring - a big pedestrian area, and shopping centre has now become an attractive feature of Birmingham.

\subsection{Motorways and pedestrianization in Vienna}

In Vienna an urban motorway was built and opened in 1978 to relieve the crowded inner urban streets from the north-south traffic crossing the Danube river. This was one of the few examples studied over a long period of time. It gave a clear indication of the effect of transport infrastructure on the safety of the whole system of a city. The number of accidents in Vienna continuously declined during the 70s. But when the motorway was opened, the trend reversed and the graph peaked in 1994, with accident figures reaching its old levels. It was the effect of this motorway which caused about 15,000 accidents. The effects are very complex and have to be understood by systems analysis and can be reproduced today by computer modelling using real human and structural behaviour of cities (Knoflacher 2004).

With the opening of the motorway the speed went up and the kinetic energy in the whole urban structure was enhanced, leading to increased safety hazards and accidents. Big shopping centres appeared at the fringes of the city and many shops in the city had to be closed. Trips became longer and planners of the urban motorway were blamed within a few years after the motorway was opened. Today Vienna is the most congested section of Austria. The congestion level has now reached a new dimension and at the same time the urban street network is more congested than it was before. In addition, the adverse economic and transport effects of these motorways have disastrous consequences on environment and health. The noise level has increased, and what is worse, air pollution problems are now much more severe than ever before. The city is now helpless to a certain extent and cannot defend itself any more because of the high speed of car traffic. These effects are inevitable and are a lesson for all of us. 
Whenever a motorway is built as part of the city structure, it has disastrous consequences all round.

Vienna is one of the most liveable cities today, and has some examples to show of another kind. In the early seventies a new transport plan for the city centre was developed (Knoflacher 1970) converting most of the streets in the city centre into pedestrian areas. This was realized in 1972 and since then the city centre of Vienna became an attraction for the region and for the country; it has become a global attraction and a global heritage. Two-thirds of the people coming into the city centre use the public transport, or come as pedestrians and cyclists. Since Vienna had no cycling tradition it had to be developed from scratch. Due to sound scientific research the city established a cycling department which built more than 800 kilometres of cycle tracks during the last twenty years. Today Vienna is one of the most famous cycling cities. Cycling brings money into a city, it makes the city attractive, it gives people health and is an excellent, cheap urban mode of transport.

The key element in Vienna that makes all other measures successful was the parking regulation. In the inner districts of Vienna no free parking space is available anymore. Most big places in the city centre are totally car-free. Earlier people used to leave the city due to adverse living conditions, air pollution and danger in public spaces, They are now beginning to come back into the recovered parts of the pedestrianized city. The city has gained importance by virtue of applying the right transport policy measures. Such future-oriented measures were able to compensate the adverse effects that motorway had on the city.

\subsection{Eisenstadt}

A small city only fifty kilometres away from Vienna, Eisenstadt with only 11,000 inhabitants, introduced in the seventies a transport policy, based on scientific principles. It was a city in economic decline with not enough working space and its people had to travel to Vienna for work. It was difficult to implement future-oriented transport policies in such a sick city, not only for planners but also for administrators and politicians. Thanks to a receptive city administration it was finally possible to introduce during the late eighties a big pedestrian area supported by some parking places around it, reorganizing the car traffic with no through traffic, building cycle tracks and improving public transport (Knoflacher 1989b). Since then the whole 'climate of the city' has changed. The city has become an attractor for shopping and working. Today people commute not from Eisenstadt to Vienna, but in the reverse direction. This shows how sound future-oriented transport planning can influence not only the city economy, but its culture and tourism.

The quality of public space is a key element in the success of a city. The quality of public space is also dependent on the presence of pedestrians, cyclists and public transport (buses, trams and light rail being the preferred modes of public transport).

\subsection{Motorways and detour roads around the city}

Today we know that problems have to be solved where they occur. Building motorways, and detour roads (there are exceptions) to solve transport problems or building flyovers to overcome congestion are totally counter-productive measures. System analysis and several practical examples can prove it. In the urban system we normally have a suppressed additional demand for car traffic. As soon as we provide more space for cars, we produce an artificial demand for long distance trips and destroy the opportunities for the local scale. The solution is an agreeable urban transport system in which the car is under the control of the administration and society and not the other way round. 


\section{Understanding the transport system}

A correct parking organization is the key for a successful, sustainable transport system. In practice, what interests professionals and politicians in the transportation system today is: (i) traffic flow of cars, (ii) congestion mitigation, (iii) road pricing, (iv) public transport subsidies, (v) telematics (ITS), (vi) urban and land use planning (based on questionable assumptions). If we look at the results of the efforts to solve transport problems in general and in urban areas in particular, the following strategies can be observed: (a) building more infrastructure (build the problem away); (b) introduce more traffic signalization (signal the problems away); (c) enhance the quantity and quality of information (ITS); (d) traffic management; (e) road pricing; and make public transport more attractive.

The outcome of the efforts over the last fifty years is discouraging. It is obvious that most strategies do not solve but create problems and are cost-ineffective. Sustainability tends to decrease and we can argue that the main features of today's transport policy are helplessness and basic ignorance.

If we examine the current transport science we have to recognize that what operates is a kind of ideology instead of rationality and in transport policy what works is an increasing populism instead of responsibility.

Humankind is fascinated with speed. Speed escalation during the early twentieth century was too much for professional disciplines, politicians and the society. Effortlessness of speed has not been understood till today. Due to rapid changes we have not had enough time to understand the systemic effects of speed, since engineers, politicians and society were happy with the new opportunities and could not recognize the losses that go hand in hand with promoting speed.

The systemic effects include the relationship between (a) land use and transport; (b) land use transport and the economy, and (c) land use transport, the economy and social systems, etc. Instead of developing sound theoretical and practical background, dogmas and myths abound in our so-called transport science. The most common dogmas and myths are: (a) growth of mobility, (b) saving time by increasing speed, (c) freedom of modal choice.

\subsection{Growth of mobility}

With increasing motorization mobility increases. The number of trips a person makes a day increases with number of cars per inhabitants. More cars mean more mobility. In the textbook of the twentieth century this was the traditional definition of mobility (figure 1). Nobody asked why mobility outside the house is necessary. Each trip is related to a purpose. This purpose is to compensate the existence of local deficits of the origin at the destination.

Mobility can therefore only increase if local deficits increase, which means poor urban planning, poor logistics, poor management. All these deficits have to be compensated by physical mobility. But the number of purposes in society have not changed during increased motorization. Mobility has nothing to do with car ownership since it is purpose-related. Each trip with the car replaces a trip of another mode (figure 2).

Increasing car mobility means decreasing mobility for pedestrians, cyclists or public transport. There is no growth of mobility in the transport system. The number of trips remains constant. An example from an Austrian city shows the effect of the changing environment (figure 3). The trend of increasing motorization was broken by changing the physical structures around 1990.

Since then car traffic has declined; pedestrian, cycling and public transport has increased. The total number of trips has not changed. The myth about the growth of mobility is based on 


$$
\text { more cars - more mobility }
$$

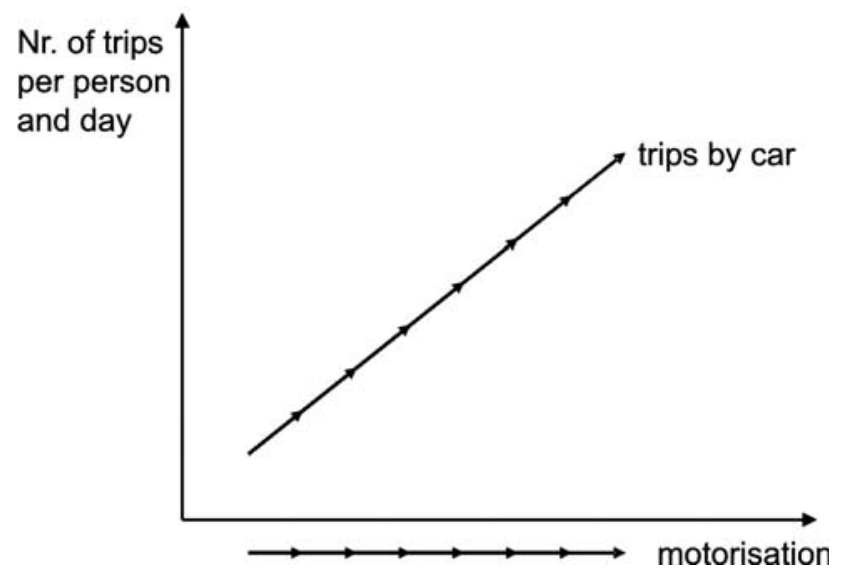

Figure 1. More cars mean more mobility - the common belief.

how a transport system is perceived and the traditional perception was restricted to car traffic flows. Counting stations are normally situated between cities.

If we use the law of gravity the number of trips between two cities or villages can be calculated. If we build a better road with higher speed, more capacity and cheaper transport between the cities, the resistant functions will decrease, so the number of trips between cities will increase (figure 4a). The internal trips in the cities (transport cells) have not been taken into account. Traditional transport engineers were very impressed with transport growth, but they did not ask themselves the question where this growth was coming from.

If we look at the system as a whole and consider all the internal trips of the two units and we know that the number of trips is constant - the growth of mobility between cities is equal to the decline of local mobility in cities (figure $4 \mathrm{~b}$ ). The resistance function in the cities has been enhanced and between the cities decreased. Motorways have been built to connect the cities and surround them and barriers have been built to separate one side of the road in the village or in the city from the other. There is no growth of mobility in the system; there is only a shift from one mode to the other.

\section{reality}

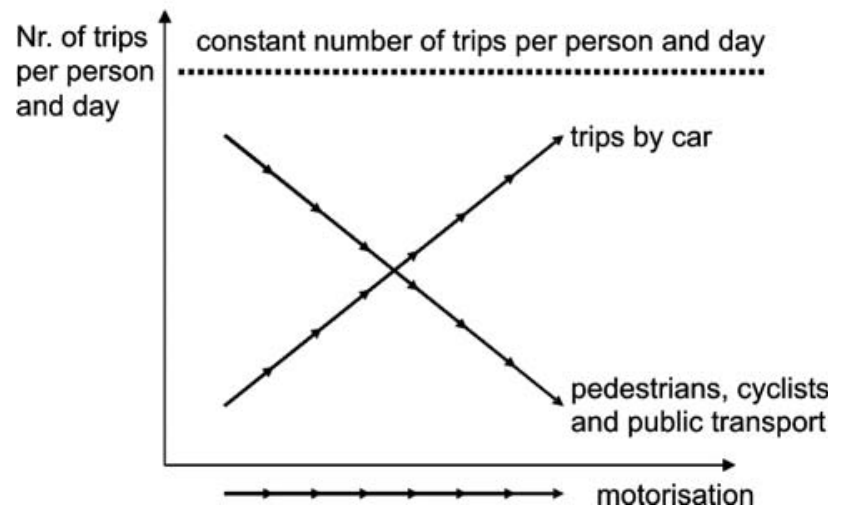

Figure 2. There is no increase of mobility, if all modes are taken into account. 


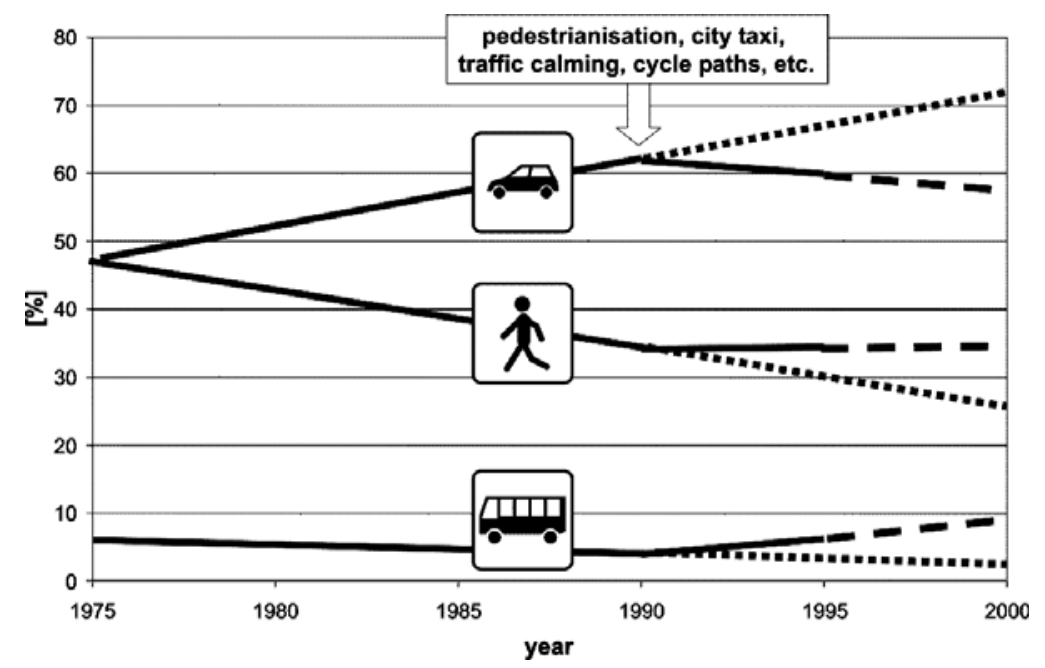

Figure 3. The kinds of mobility would change if the structures are changed by qualified planning decisions.

\subsection{Saving time by increasing speed}

All investments in transport infrastructure are based on calculations, which assume less travel time by increasing speed (figure 5 ).

The average travel speed of the Austrian population for individual trips (pedestrians, cyclists, motorcyclists, and car users) for the time period from 1955 to 1981 is shown in figure 6.

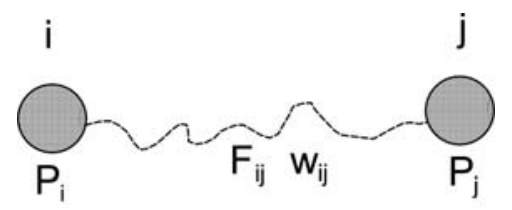

(a)

$$
F_{i j}=\frac{P_{i} \cdot P_{j}}{W_{i j}}
$$

i

j (b)

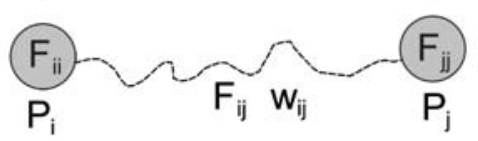

$F=F_{i i}+F_{i j}+F_{i j}=F_{i i}+\frac{P_{i} \cdot P_{j}}{W_{i j}}+F_{i j}$

$\delta \mathrm{F}=0 \ldots$ constancy of number of trips!

Figure 4. (a) Car traffic was mainly counted between cities. (b) System view of qualified professionals. 


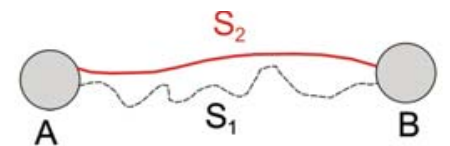

Speed: $v_{2}>v_{1}$

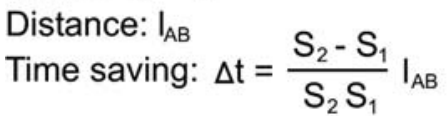

Benefit $=\operatorname{Sum}(\Delta t \cdot$ money per time $)$

CB-factor $=$ benefits/costs $>1$ (3)
Figure 5. A common method of calculating benefits from increasing speed.

Due to increasing motorization the average travel speed for individuals in Austria was enhanced about ten times. If increasing speed produces time saving, the Austrian population would have saved a huge amount of time. But this is in complete contradiction with results from the system data. If we use the data for travel time for different modes for different cities or countries we always get a similar figure (figure 7).

Travel time distributions of pedestrians, cyclists, car drivers and motorcyclists are always the same. There is no difference between them even if there are big differences in travel speed. These data from the seventies (figure 8 ) are supported by a study carried out by Schafer (1998).

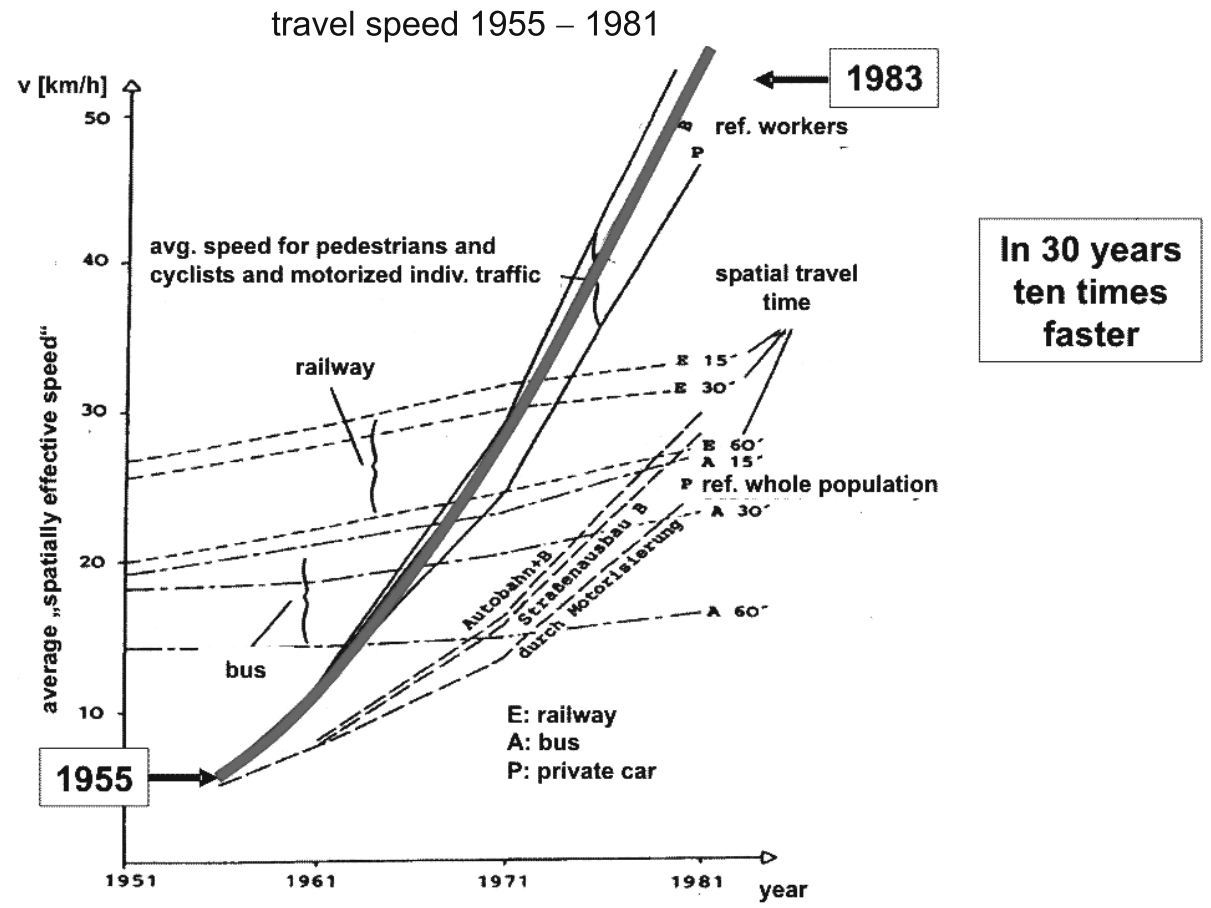

Figure 6. Increase of individual travel speed in Austria 1955-1981 (Knoflacher 1985) . 


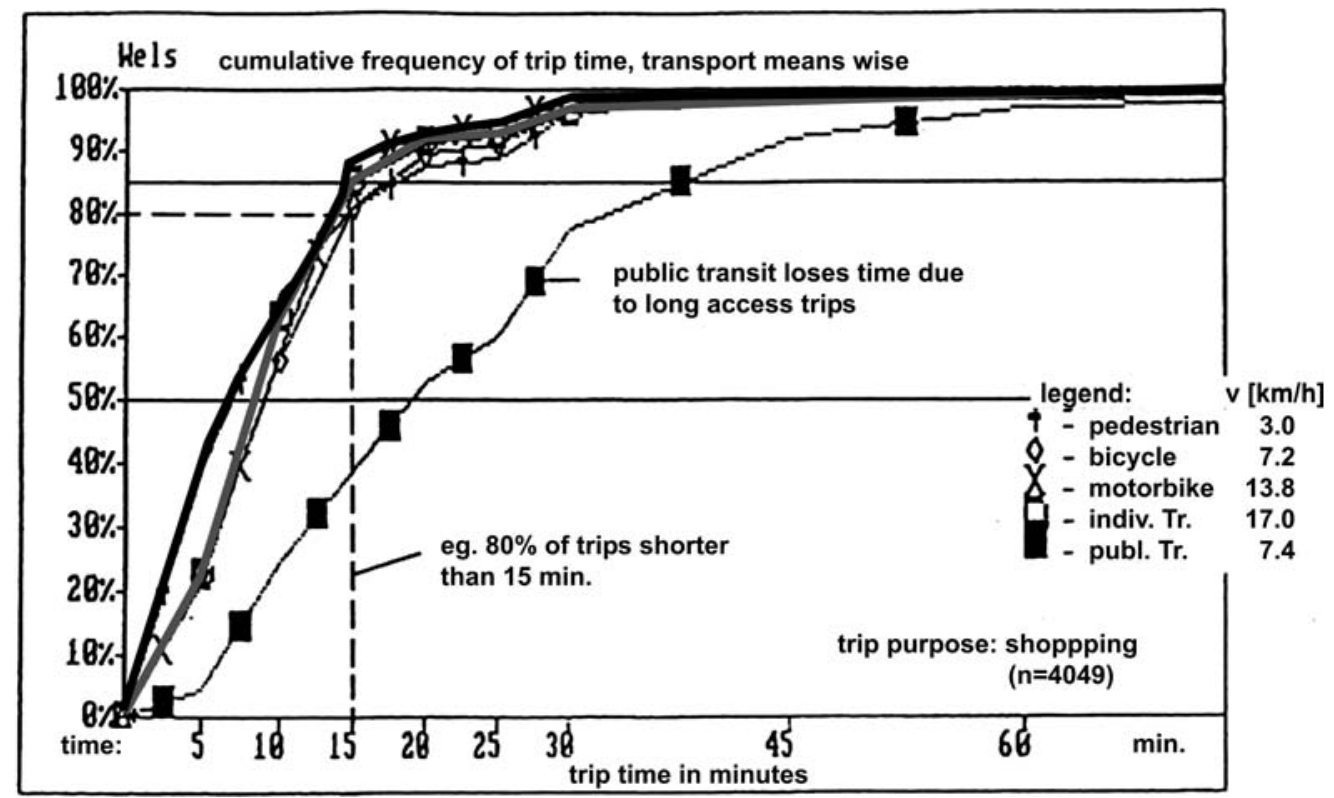

Figure 7. Travel time distribution of different modes shows no differences (Knoflacher 1989a).

Poor people have no cars and have to walk at pedestrian speed. Rich societies have a lot of cars, travel at high speeds, but the travel time budget is the same everywhere in the world. Since travel time does not change with increasing speed, the distance must change (figure 9).

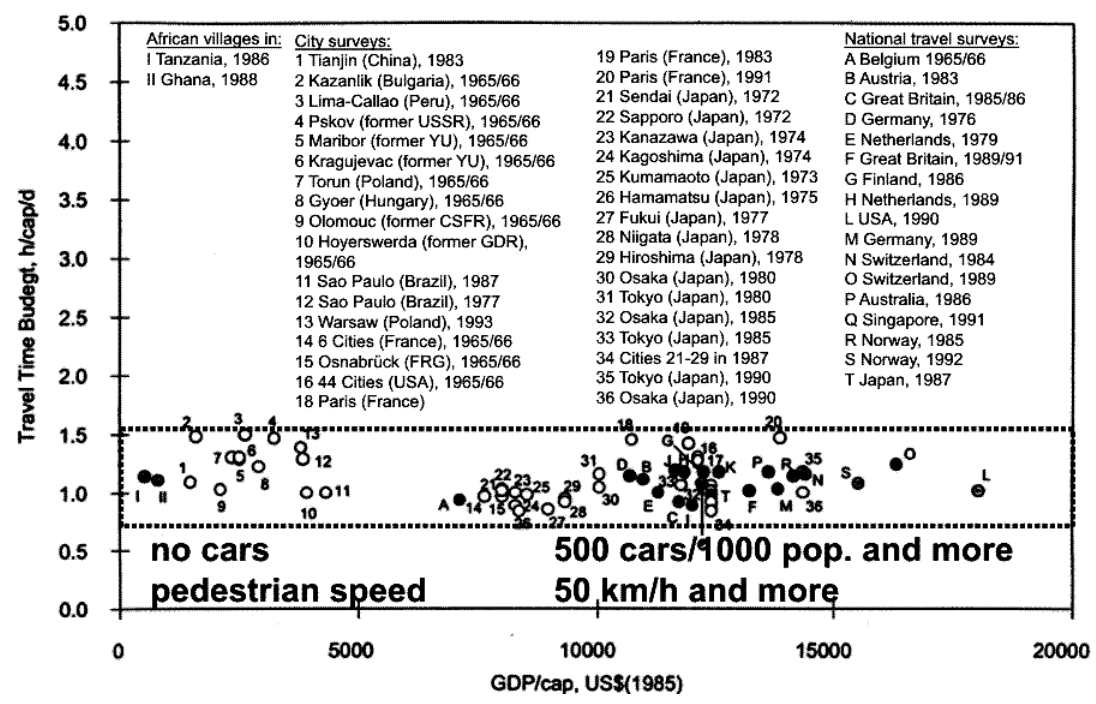

The travel time budget is everywhere the same!

Figure 8. Global data shows that speed of travel does not result in overall trip times (Schafer 1988). 


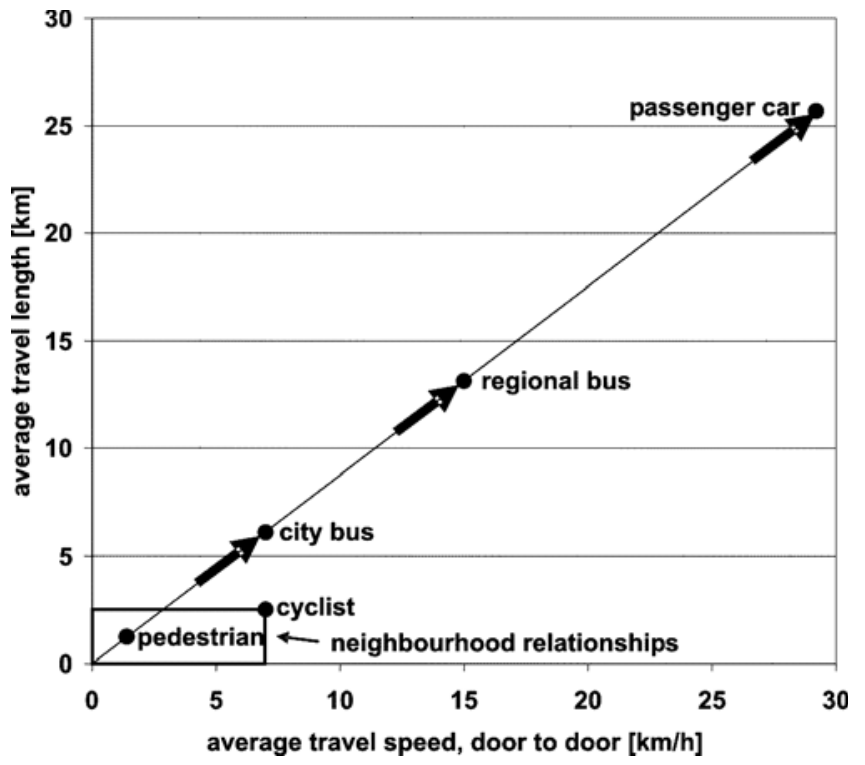

Figure 9. Higher speed - longer distances (Nahverkehrskommission 1986).

If travel time is increased, distance is enhanced. Since each trip has a purpose local activities disappear and are replaced by activities in distant locations. This sound theoretical basis can now explain two main effects of the last hundred years:

(a) Urban sprawl-urban sprawl is only possible on the basis of high speed, fast transport systems and cheap (individual) mobility. Transport system destroys the urban form; instead of cities, agglomerations occur.

(b) Concentration-economic activities have to be concentrated at the same time due to principles of economy of scale. The result is big shopping centres on inexpensive ground, very often far away from cities. These economic structures destroy the base of the urban economy.

\subsection{Congestion - a problem}

Traditional transport engineers believe that congestion is a problem. There are very few empirical observations about real human behaviour if congestion appears.

If traffic flow exceeds the capacity of a road, traditional transport engineers tend to add additional lanes to reduce density and enhance the speed. This is the effect of traditional transport education. If density is decreased, the car transport sector becomes more attractive, more people use the car, the speed is enhanced not only locally; this produces more car traffic and finally the same congestion appears, but only on a higher level. This is the inevitable outcome of traditional transport treatment methods. This has been studied on an urban motorway in Vienna where traditional transport planning had forecast a reduction in traffic flow when the motorway was opened. Ten years later, the urban roads had more traffic than before and there was about four times more car traffic on the motorway. This was because the motorway produced its own urban structure consisting of urban sprawl and economic activities along the motorways (figure 10). 


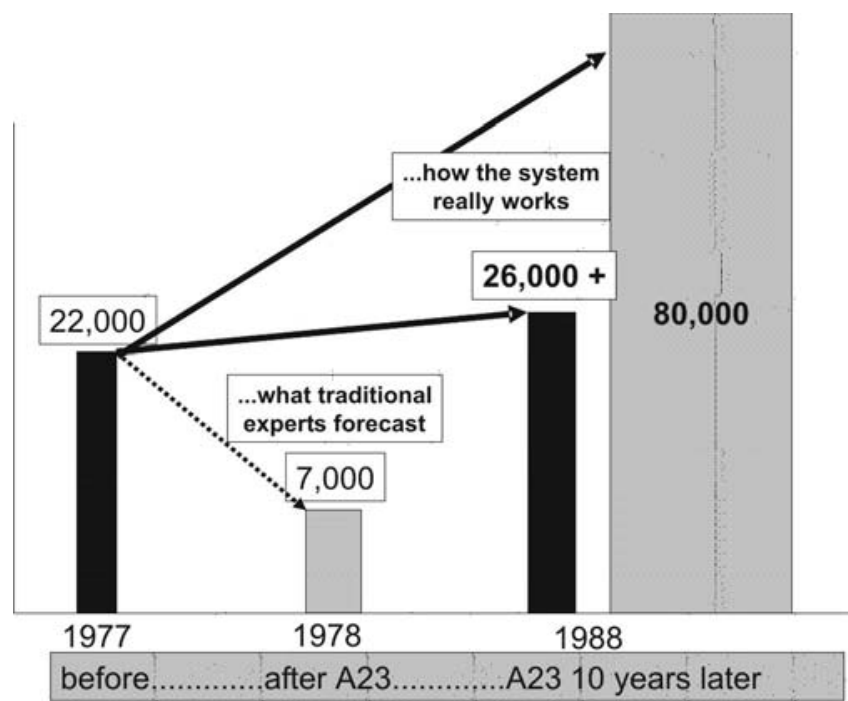

Figure 10. The difference between the immediate effect (the expectation of traditional transport science) and the systemic effect - ten years later (Knoflacher 2007).

\subsection{Freedom of modal choice}

Since humans have invented new transport modes they are also able to control and master them. We are able to park our cars at home but expected to use public transport. When we don't use public transport we are punished by congestion/road pricing.

Research in Vienna and other cities in Europe have shown that the acceptance of public transport decreases with distance of public transport from home (figure 11).

It is also influenced by environment. This function, derived from human behaviour observing is also well known from research about the behaviour of bees' (figure 12).

The acceptance of distance decreases in an exponential form. This is the case for bees (for flying) as well as for people (for walking). In both cases body energy consumption is the cause for such behaviour (Knoflacher 1981a) and this has far-reaching effects (figure 13).

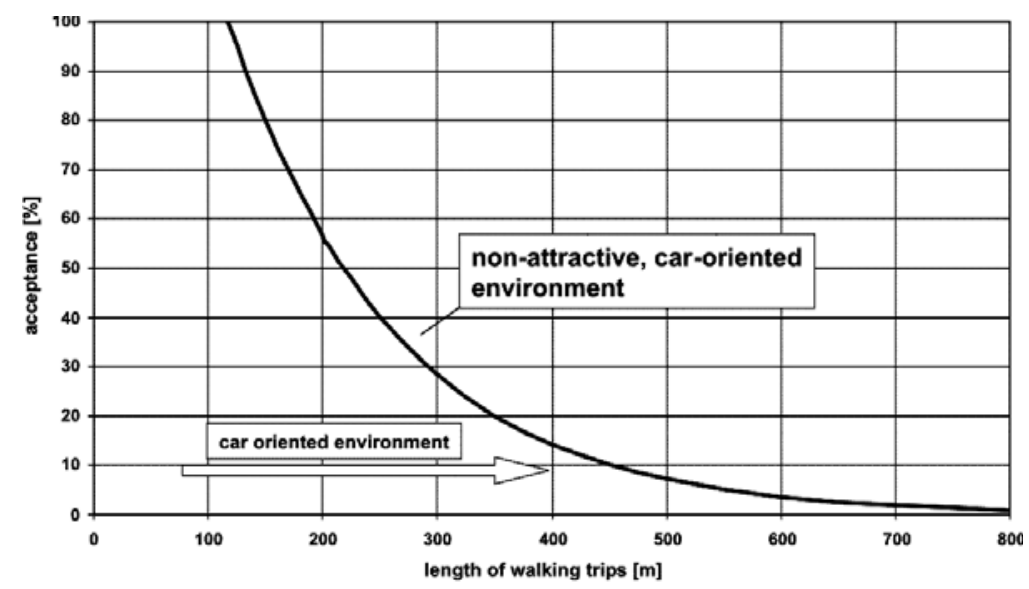

Figure 11. Acceptance function for pedestrians in a car-oriented environment (Peperna 1982). 


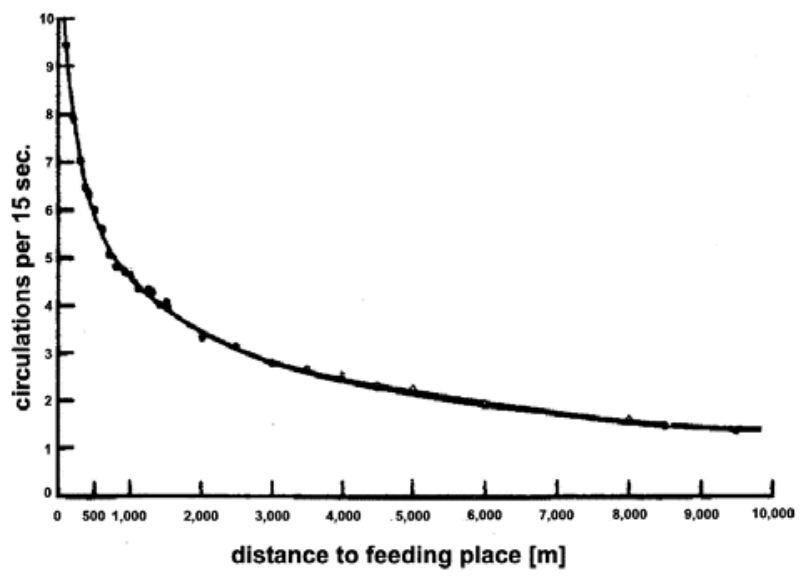

Figure 12. Bee behaviour as observed by Frisch (1965).

The car is the innovation of our technical civilization, but has adverse effects on our oldest and most powerful level of evolution: the level of body-energy. Body energy is much more powerful than the culture or politics. If the body energy level is changed, human behaviour also changes. This happened during the last 50 years in transport sector. We can demonstrate it with simple examples concerning the basic rights of humans in public space. If pedestrians were to behave in the same manner as car drivers and use the same amount of space, they could demonstrate their power by using a kind of 'walking tool' as shown in figure $14 a, b$.

But if a pedestrian would use the public space in such a way, he would be called crazy by our society. The misuse of public space especially in urban areas is the so-called congestion problem in all European countries. The same is true with the parking problem. It seems totally crazy to leave four empty slots in the precious public space to block all other activities, and act as a barrier to pedestrians, cyclists, trees, etc. (figure 14c).

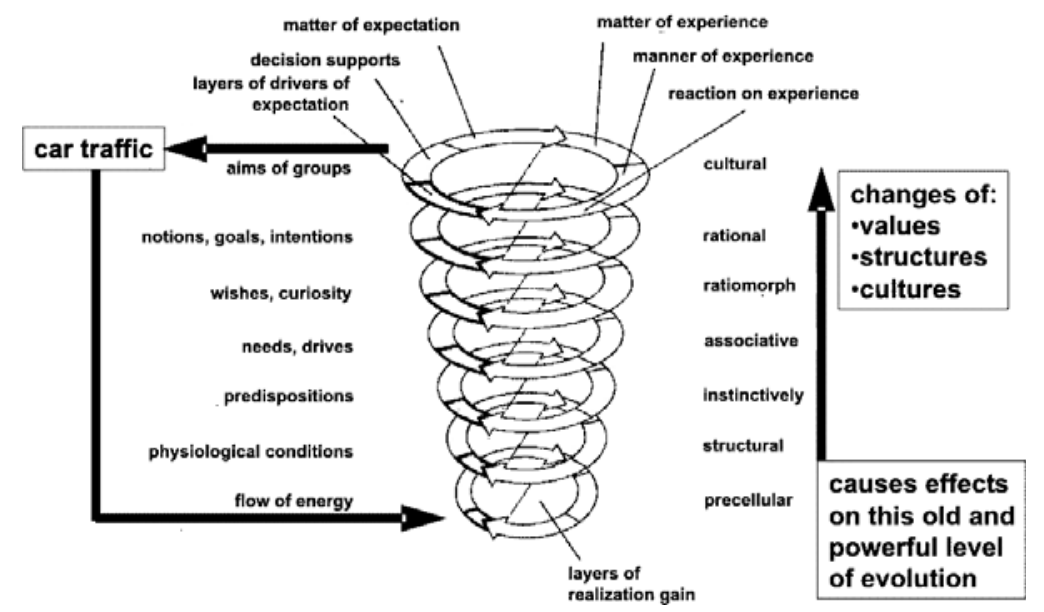

Figure 13. Innovation of our technical civilization has effects on our body energy use and affects our oldest and most powerful levels of human evolution (Riedl 1985). 


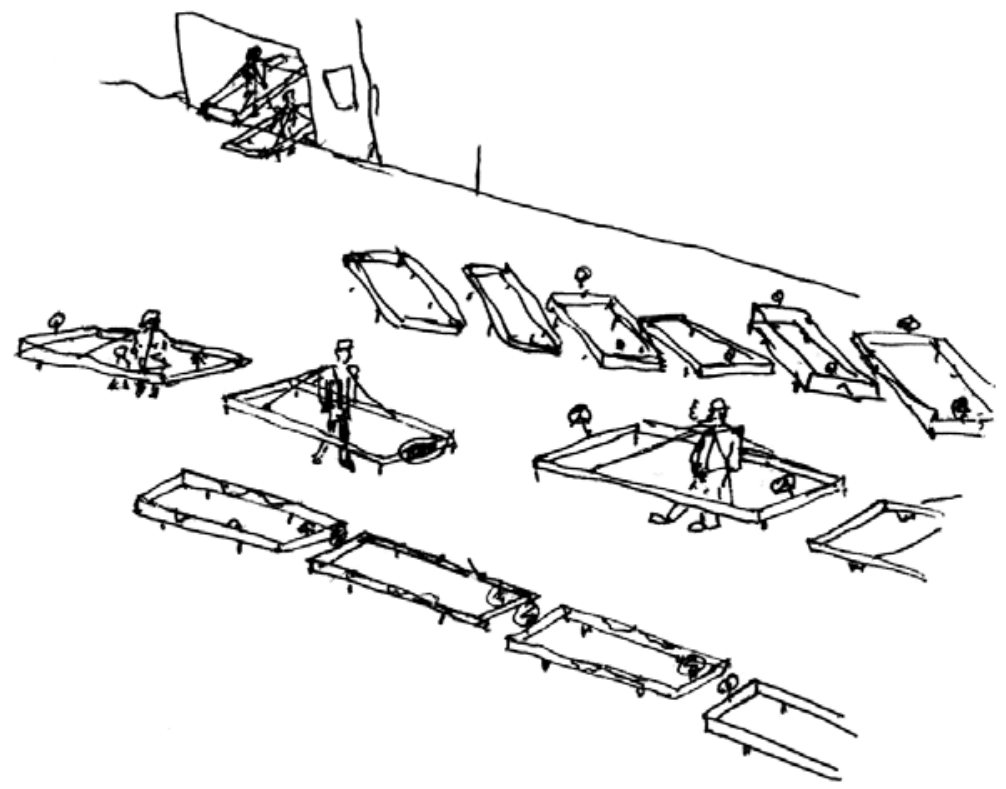

Figure 14a. If pedestrians were to use the same amount of public space as car drivers (Knoflacher 2001).
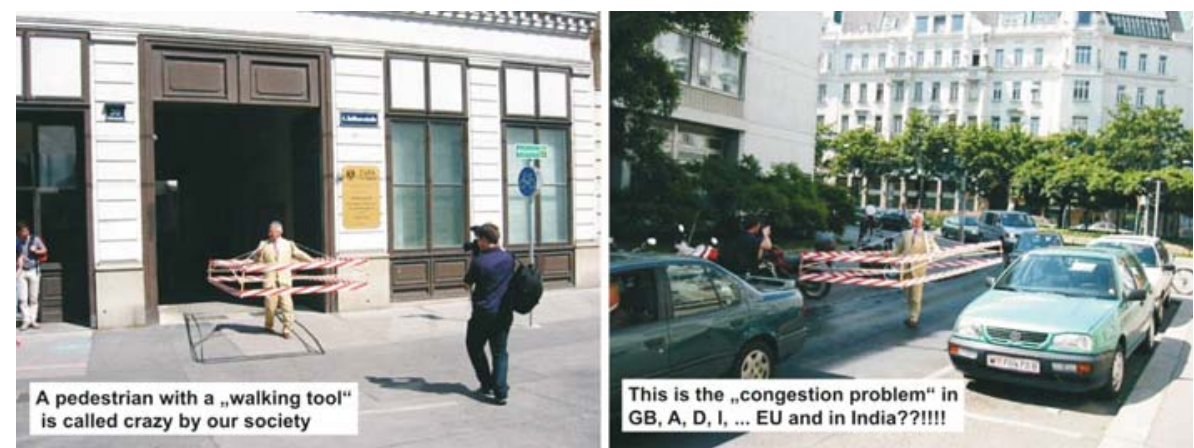

Figure 14b. Pedestrians with car-like 'walking tools'.
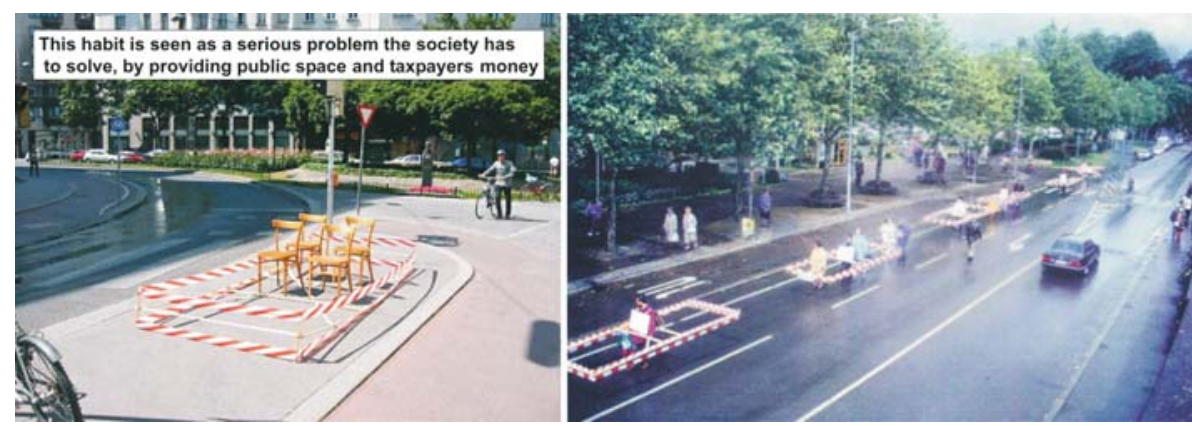

Figure 14c. The 'Parking' and 'Congestion' problems from a human perspective. 
This is the key problem of the transport system of today: the car is parked adjacent to all human activities. Nearby parking replaces everything in the neighbourhood. Parking at home transforms people into car drivers. It destroys all human scale structures and activities. The separation of activities is the result of individual optimization of parking. Public transport under these circumstances has no chance anymore. This is the key element of urban sprawl, because the house and the garage do not need any seat around it. Shopping centres plus parking place do not need any built-up environment; it can be situated anywhere. What is needed is only an access to the motorway.

\section{The solution}

Intelligent planning and treatment means the problem has to be treated at the source where it occurs. The solution therefore cannot be found in treatment of flow in traffic, or in road pricing or in tariffs of public transport. The intelligent solution lies in reorganization of origins and destinations - a fundamental reorganization of parking.

\subsection{The physical structure has to be changed}

Equity between cars and public transport would be necessary everywhere. This means the walking distance to a parking place has to be at least as long as the walking distance to the public transport stop (Knoflacher 1989b). Cars have to be stored in garages, situated as far away as public transport stops (figure 15).

\subsection{The financial structure}

The whole transport sector does not even follow the basic principles of market economy. Whoever parks the car at home must pay more, whoever parks it in the right place should pay less. Whoever parks his car at a distance equal to the distance of the public transport should have to pay a fee equal to the annual public transport ticket which he also gets. Who

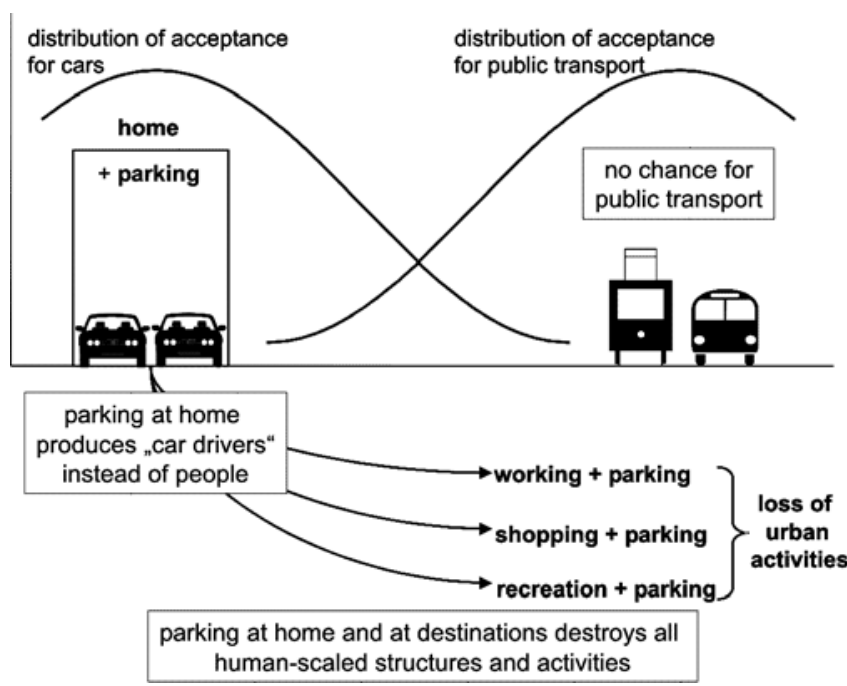

Figure 15. This is the key problem of the transport system of today — the wrong parking organization. 


\section{precondition for a liveable city:}

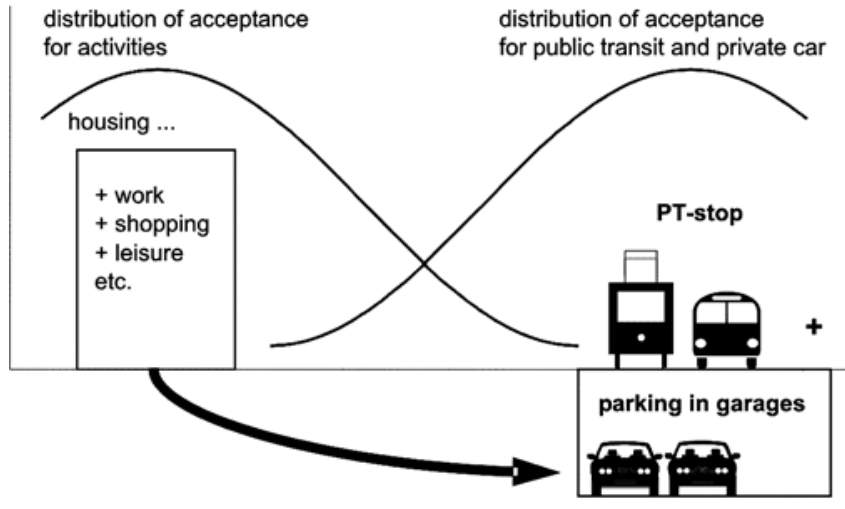

equal distance to the parking place and the public transport stop (PP = PTS)
Figure 16. Parking at home (and the destination) destroys human settlements, etc. (Knoflacher 1981b).

parks at home or in front of his house should be required to pay an amount according to the attractiveness curve $\mathrm{x}$-times the annually public transport ticket, but he gets only one ticket. The same principle has to be introduced at the destination, at working places, at shops, at recreation and business areas.

\subsection{Organization structure}

Transport has not been organized as a system. Interlinked parts have been optimized in isolation without taking into account the effects on the whole system. The worst mistake is the optimization of parking on an individual level. If this happens, no optimization of the system is possible anymore (figure 16).

Parking places in our market economy have to be treated in accordance with the reality of human behaviour: (i) equidistance to parking lots and public transport stops; (ii) the price has to reflect the real value or privilege; and (iii) transport has to be organized as a system.

\subsection{Traditional transport beliefs and scientific transport management}

Table 1 shows the difference between traditional transport planners' beliefs and evidence based policy.

Table 1. Scientific-based transport management.

Traditional transport beliefes shared by EU policies

- Belief in growth of mobility

- Belief in time saving by increasing speed

- Belief in freedom of modal choice
Scientific based transport management

- There is no growth of mobility in the transport system

- No time saving in the transport system is possible

- Real behaviour of people structures determine behaviour 


\section{Conclusion}

There can be no solution for a sustainable future of the traffic problem through conventional methods and measures. If we do not learn from the past, we have no chance of surviving in the future. In the past the share of public transport has been destroyed, not by increasing the number of cars but by organizing parking in a wrong manner. With an increasing number of cars per inhabitant, the share of public transport follows a fundamental law discovered by the author in 1980 in a precise way (Knoflacher 1980). In future, we need more energy-efficient transport modes than in the past. Compared to non-motorized modes all mechanical modes are more energy-inefficient.

The lowest efficiency has car traffic - less than $1 \%$ of non-motorized modes and the use of this transport mode has to be reduced for rare occasions in the future. Countries with a low degree of motorization have the opportunity to prevent mistakes in the transport system or repeat them.

\section{References}

Frisch K V 1965 Tanzsprache und Orientierung der Bienen (Berlin-Heidelberg-New York: SpringerVerlag)

Knoflacher H 1970 Verkehrsorganisation I Bezirk. Studie durchgeführt im Auftrag des Magistrats der Stadt Wien (Wien: Magistratsanteilung 18 - Stadt- und Landesplanung).

Knoflacher H 1980 Öffentliche Verkehrsmittel - Neue Strukturen zur Verbesserung ihrer Chancengleichheit im städtischen Bereich, Internationales Verkehrswesen 32: 176-178

Knoflacher H 1981a Human energy expenditure in different modes: implications for town planning. International Symposium on Surface Transportation System Performance (Washington DC: US Department of Transportation).

Knoflacher H 1981b Zur Frage des Modal Split. Straßenverkehrstechnik, 25. Jg., 5: 150-154

Knoflacher H et al 1985 Raumwirksamkeit von Verkehrssystemen. Schriftenreihe Straßenforschung Nr. 268 (Wien: Bundesministerium für Bauten und Technik).

Knoflacher H 1989a Generalverkehrsplan Wels. Durchgeführt im Auftrag des Magistrats der Stadt Wels.

Knoflacher H 1989b Verkehrskonzept Eisenstadt. Durchgeführt im Auftrag der Landeshauptstadt Freistadt Eisenstadt.

Knoflacher H 2001 Stehzeuge. Der Stau ist kein Verkehrsproblem (Wien: Böhlau Verlag)

Knoflacher H 2004 Effect of an Motorway on Accidents in a Big City. The Balaton Bulletin, (Toronto: Balaton Group Inc.) 11-12

Knoflacher, H 2007 Grundlagen der Verkehrs- und Siedlungsplanung: Verkehrsplanung (Wien - Köln - Weimar: Böhlau Verlag).

Nahverkehrskommission 1986 Nahverkehrskonzept Zentralraum Salzburg, Verkehrsuntersuchung 1982 (Salzburg: Amt der Salzburger Landesregierung, Abt. VI).

Peperna O 1982 Die Einzugsbereiche von Haltestellen öffentlicher Nahverkehrsmittel im Straßenbahnund Busverkehr. Diplomarbeit am Institut für Verkehrsplanung der Technischen Universität Wien.

Riedl R 1985 Die Spaltung des Weltbildes. Biologische Grundlagen des Erklärens und Verstehens. (Berlin und Hamburg: Verlag Paul Parey).

Schafer A 1998 The global demand for motorized mobility. Transportation Research Part A 32(6): $455-477$ 